\title{
Effect of green tea on resting energy expenditure and substrate oxidation during weight loss in overweight females
}

\author{
Kristel Diepvens ${ }^{1}$, Eva M. R. Kovacs ${ }^{2}$, Ilse M. T. Nijs ${ }^{1}$, Neeltje Vogels ${ }^{1}$ and Margriet S. Westerterp-Plantenga ${ }^{1}$ \\ ${ }^{1}$ Maastricht University, Maastricht, The Netherlands \\ ${ }^{2}$ Unilever Food and Health Research Institute, Unilever R\&D Vlaardingen, Vlaardingen, The Netherlands
}

(Received 7 April 2005 - Revised 20 June 2005 - Accepted 14 July 2005)

\begin{abstract}
We assessed the effect of ingestion of green tea (GT) extract along with a low-energy diet (LED) on resting energy expenditure (REE), substrate oxidation and body weight as GT has been shown to increase energy expenditure and fat oxidation in the short term in both animals and people. Forty-six overweight women (BMI 27.6 (SD 1.8$) \mathrm{kg} / \mathrm{m}^{2}$ ) were fed in energy balance from day 1 to day 3, followed by a LED with GT $(1125 \mathrm{mg}$ tea catechins $+225 \mathrm{mg}$ caffeine/d) or placebo (PLAC) from day 4 to day 87. Caffeine intake was standardised to $300 \mathrm{mg} / \mathrm{d}$. Energy expenditure was measured on days 4 and 32 . Reductions in weight (4.19 (SD 2.0) kg PLAC, 4.21 (SD 2.7) kg GT), BMI, waist:hip ratio, fat mass and fat-free mass were not statistically different between treatments. REE as a function of fat-free mass and fat mass was significantly reduced over $32 \mathrm{~d}$ in the PLAC group $(P<0 \cdot 05)$ but not in the GT group. Dietary restraint increased over time $(P<0.001)$ in both groups, whereas disinhibition and general hunger decreased $(P<0 \cdot 05)$. The GT group became more hungry over time and less thirsty, and showed increased prospective food consumption compared with PLAC $(P<0 \cdot 05)$. Taken together, the ingestion of GT along with a LED had no additional benefit for any measures of body weight or body composition. Although the decrease in REE as a function of fat-free mass and fat mass was not significant with GT treatment, whereas it was with PLAC treatment, no significant effect of treatment over time was seen, suggesting that a robust limitation of REE reduction during a LED was not achieved by GT.
\end{abstract}

Green tea: Weight loss: Resting energy expenditure: Substrate oxidation

Overweight and obesity represent a rapidly growing threat to the health of populations in an increasing number of countries (World Health Organization, 2000). The ultimate cause of obesity is an imbalance between energy intake and energy expenditure (EE; Stunkard, 1996). A negative energy balance is needed to produce weight loss and can be achieved by either decreasing intake or increasing expenditure. Classical weight loss programmes, such as low-fat diets, behavioural modification and exercise, often fail to achieve a long-term maintenance of weight loss (Wadden et al. 1988; Pasman et al. 1999a). Because of these low success rates, the stimulation of EE (or the prevention of its decline during dieting) by the use of natural herbal nutrients has attracted interest. One of these agents is green tea (GT), which is consumed primarily in China, Japan and a few countries in North Africa and the Middle East (Graham, 1992; Weisburger, 1997).

Tea is made from the leaves of Camellia sinensis L. species of the Theaceae family, GT being the non-oxidised, non-fermented product. As a consequence of this, it contains high quantities of several polyphenolic components such as epicatechin, epicatechin gallate, epigallocatechin and, the most abundant and probably the most pharmacologically active, epigallocatechin gallate (Kao et al. 2000).

GT extracts, containing caffeine and catechin-polyphenols, have been reported to have an effect on body weight (Kao et al.
2000; Chantre \& Lairon, 2002) and EE (Dulloo et al. 1999, 2000). It has been reported that in vitro caffeine has thermogenic effects and can stimulate fat oxidation, in part via sympathetic activation of the central nervous system (Dulloo et al. 1992). In humans, caffeine has been shown to stimulate thermogenesis and fat oxidation (Dulloo et al. 1989; Astrup et al. 1990; Bracco et al. 1995). The fact that GT stimulates thermogenesis cannot be completely attributed to its caffeine content because the thermogenic effect of GT is greater than that of an equivalent amount of caffeine (Dulloo et al. 1999). Dulloo et al. (2000) found that catechin-polyphenols increased the respiration rate of brown adipose tissue in vitro, thus stimulating thermogenesis. The catechins in GT may stimulate thermogenesis and fat oxidation through an inhibition of catechol O-methyl-transferase, an enzyme that degrades noradrenaline (Borchardt \& Huber, 1975). Studies in man have shown that GT stimulates thermogenesis and fat oxidation in the short term (Dulloo et al. 1999). GT might thus act at different steps of the noradrenaline modulatory pathways and in this way exert a thermogenic and possibly an anti-obesity effect (Dulloo et al. 1999, 2000; Kao et al. 2000).

There are few data about the effects of GT on thermogenesis and substrate oxidation (Dulloo et al. 1999), especially when supplemented for a longer period of time. There are also no data available on the effects of GT supplementation combined with a low-energy diet (LED). This is of interest as it is well 
established that energy restriction and weight loss may cause a sustained suppression of resting energy expenditure (REE), which is a risk factor for weight regain (Ravussin et al. 1988; Ravussin \& Bogardus, 1992; Astrup et al. 1999; Menozzi et al. 2000). We hypothesised that GT ingestion during a LED might compensate for the reduction in REE and prevent weight regain and thus weight-cycling (the yo-yo effect). Because of possible interactions between GT and habitual caffeine intake level, we investigated the effect of GT in the context of a controlled but realistic caffeine level (Kovacs et al. 2004). The aim of the present study was therefore to investigate whether GT ingestion, independent of habitual caffeine intake, increased REE and substrate oxidation, whether this effect was present after a 4-week administration of GT along with a LED (meal replacement diet plan) and whether GT ingestion during the LED offset the expected reduction in REE. Furthermore, we investigated the effect of a 12-week GT administration during the LED on body weight and fat loss. We hypothesised that GT might increase REE and fat oxidation compared with PLAC, and that this effect might be present after a 4-week ingestion of GT along with a LED (meal replacement diet plan). We further hypothesised that GT might offset the reduction in REE that is expected to occur during the LED and that GT might stimulate the loss of body weight and fat.

\section{Methods}

Subjects

Forty-six overweight women, aged between 19 and 57 years and with a BMI of between 25 and $31 \mathrm{~kg} / \mathrm{m}^{2}$, participated in this study. The subjects were recruited by advertisements in local newspapers. All volunteers ( $n$ 57) participated in an initial screening that involved the measurement of body weight, height, waist:hip circumference ratio and blood pressure, the completion of questionnaires related to health, use of medication, smoking behaviour, alcohol consumption and physical activity, and a food history questionnaire, specific for caffeine and catechin-containing products. All subjects selected ( $n 46)$ were moderate caffeine-users (200-400 mg caffeine/d; van Dam \& Feskens, 2002; Hulshof et al. 2003; van Boxtel et al. 2003; Kovacs et al. 2004), in good health, non-smokers, normotensive, not using medication and, at most, moderate alcohol users. The subjects were matched for age, BMI, weight, height, systolic and diastolic blood pressure, heart rate and caffeine intake in two groups. The two groups were randomly assigned to the two treatments: the GT treatment ( $n$ 23) and the PLAC treatment (PLAC; $n 23$ ). The baseline characteristics of the subjects are presented in Table 1.

The subjects gave their written informed consent, and the Medical Ethical Committee of Maastricht University approved the study.

\section{Experimental design}

Before the start of the study, a pilot experiment was conducted in order to determine the dosage of GT. Four female overweight subjects (age 37.5 (SD 13.1) years, BMI 25.8 (SD 1.6) $\mathrm{kg} / \mathrm{m}^{2}$ ) participated in this experiment, which consisted of three indirect calorimetry tests. The day before the test, the subjects' food and caffeine intake were standardised by the investigators. On the day
Table 1. Subject characteristicsł at baseline

\begin{tabular}{|c|c|c|c|c|}
\hline & \multicolumn{2}{|c|}{ Placebo (n 23) } & \multicolumn{2}{|c|}{ Green tea $(n 23)$} \\
\hline & Mean & SD & Mean & SD \\
\hline Age (years) & 41.6 & $10 \cdot 0$ & $41 \cdot 7$ & 8.6 \\
\hline Height $(m)$ & 1.66 & 0.05 & 1.66 & 0.05 \\
\hline Weight (kg) & $76 \cdot 3$ & $6 \cdot 6$ & $76 \cdot 4$ & $6 \cdot 3$ \\
\hline BMI $\left(\mathrm{kg} / \mathrm{m}^{2}\right)$ & $27 \cdot 7$ & 1.8 & $27 \cdot 7$ & $1 \cdot 8$ \\
\hline Fat-free mass (kg) & $47 \cdot 3$ & 4.5 & $47 \cdot 2$ & $3 \cdot 2$ \\
\hline Body fat (\%) & $38 \cdot 0$ & $4 \cdot 4$ & $38 \cdot 1$ & $4 \cdot 1$ \\
\hline Waist circumference $(\mathrm{cm})$ & $84 \cdot 0$ & $6 \cdot 0$ & $85 \cdot 6$ & $6 \cdot 2$ \\
\hline Hip circumference $(\mathrm{cm})$ & $107 \cdot 0$ & 4.9 & $105 \cdot 6$ & 3.8 \\
\hline Waist:hip ratio & 0.79 & 0.06 & 0.81 & 0.05 \\
\hline Systolic blood pressure $(\mathrm{mmHg})$ & $122 \cdot 5$ & $13 \cdot 2$ & $127 \cdot 4$ & $11 \cdot 8$ \\
\hline Diastolic blood pressure $(\mathrm{mmHg})$ & $78 \cdot 6$ & 8.9 & $80 \cdot 0$ & $12 \cdot 0$ \\
\hline Heart rate (beats/min) & $66 \cdot 2$ & $6 \cdot 8$ & $65 \cdot 3$ & $7 \cdot 7$ \\
\hline Caffeine $(\mathrm{mg} / \mathrm{d})$ & $311 \cdot 8$ & $61 \cdot 1$ & $300 \cdot 2$ & $54 \cdot 5$ \\
\hline
\end{tabular}

‡ Subjects matched for characteristics; no differences between groups were statistically significant $(P<0.05)$.

of the test, REE and substrate oxidation were measured by means of an open-circuit, ventilated-hood system with subjects, in the fasted state, lying supine for $30 \mathrm{~min}$. The subjects then received a dose of one of three treatments: PLAC; low-dosage GT (50 mg caffeine, $250 \mathrm{mg}$ catechins) or high-dosage GT (75 mg caffeine, $375 \mathrm{mg}$ catechins), together with a meal replacement drink (Slim-Fast ${ }^{\circledR}$ ready-to-drink shake, French vanilla, 903 kJ; Unilever Bestfoods Nederland BV, Rotterdam, The Netherlands). EE and substrate oxidation were measured for $180 \mathrm{~min}$ after ingestion of the treatment. We concluded that there was a significant increase in diet-induced thermogenesis with the combined intake of the meal replacement drink and high-dosage GT capsules, compared with low-dosage GT. It was therefore proposed that further longterm research on the thermogenic effects of GT should focus on the high dosage of tea catechins and caffeine.

A double-blind, placebo-controlled, parallel design was adopted. The experimental design consisted of an intervention period lasting $87 \mathrm{~d}$. During days 1-87, all subjects' background caffeine intake was standardised at $300 \mathrm{mg} / \mathrm{d}$ (the equivalent of about three $150 \mathrm{ml}$ cups of coffee) in order to maintain their habitual caffeine intake (van Dam \& Feskens, 2002; Hulshof et al. 2003; van Boxtel et al. 2003; Kovacs et al. 2004). The subjects consumed a cup of coffee before breakfast $(08.00 \mathrm{~h})$, in the morning $(10.00 \mathrm{~h})$ and in the afternoon $(14.00 \mathrm{~h})$. The subjects were asked to abstain from other caffeine-rich products such as tea, cola-type soft drinks and energy drinks.

During days 1-3, subjects consumed a standardised energybalance diet at $100 \%$ of EE estimated by means of the 'body weight' computer simulation programme, which includes body weight, an average physical activity level of 1.6 and the estimated basal energy expenditure (Westerterp et al. 1995a).

During days 4-87, subjects consumed a LED in order to lose weight. The diet was a meal-replacement diet plan (Slim.Fast; Unilever Bestfoods Nederland BV), which is in accordance with $60 \%$ of the predicted EE (average percentage energy: protein 25 , fat 15 , carbohydrate 60 ). The subjects consumed a Slim.Fast meal replacement (ready-to-drink shake, soup, bar, pasta) at breakfast and lunch, and received instructions about the type and amount of food that they could ingest at dinner and as snacks. In addition, the subjects ingested three capsules (hard gelatine, size no. 1) of PLAC (Maltodextrin) or GT three times 
daily, at breakfast $(09.00 \mathrm{~h})$, lunch $(13.00 \mathrm{~h})$ and dinner $(18.00 \mathrm{~h})$. The composition and dose of the treatments is presented in Table 2.

Measurements took place in the fasted state on days 4, 32 and 87. In addition, on the morning of days 4 and 32, an indirect calorimetry test was performed. Because a variation in EE may occur in premenopausal women across the menstrual cycle, both tests were performed with subjects in the same phase of their cycle.

\section{Open-circuit, ventilated-hood test}

On days 4 and 32, REE, fat and carbohydrate oxidation were measured for $30 \mathrm{~min}$, and $\mathrm{EE}$, fat and carbohydrate oxidation were measured for $180 \mathrm{~min}$ after the ingestion of a breakfast (Slim.Fast ready-to-drink shake, French vanilla, $903 \mathrm{~kJ}$ ) and the treatment (three GT or PLAC capsules). The test was performed by means of an open-circuit, ventilated-hood system with the subjects lying supine (Schoffelen et al. 1997). Gas analysis was performed by a paramagnetic $\mathrm{O}_{2}$ analyser (OmniCal type 1155B; Crowborough, Sussex, UK) and an IR $\mathrm{CO}_{2}$ analyser (OmniCal type 1520/1507). EE was calculated using Weir's formula (Weir, 1949). The RQ was calculated as $\mathrm{CO}_{2}$ produced/O $\mathrm{O}_{2}$ consumed. Relative diet-induced EE (\% energy intake) was determined using the formula:

$\{180 \min \times[\mathrm{EE}(\mathrm{kJ} / \mathrm{min})-\operatorname{REE}(\mathrm{kJ} / \mathrm{min})] / 903 \mathrm{~kJ}\} \times 100 \%$

where $903 \mathrm{~kJ}$ reflects the energy content of the shake.

\section{Measurements}

Anthropometric measurements were taken in the fasted state during screening and on days 4, 32 and 87. Body weight was measured using a digital balance accurate to $0.02 \mathrm{~kg}$ (ChyoMW-150K; Chyo, Japan) with subjects in underwear after voiding

Table 2. Composition and dose of the treatments

\begin{tabular}{|c|c|c|c|}
\hline & GT‡ & PLAC & \\
\hline Caffeine & $26 \cdot 3$ & & \\
\hline Total catechins & $134 \cdot 1$ & & \\
\hline Catechin & 3.5 & & \\
\hline Epicatechin & $14 \cdot 0$ & & \\
\hline Epigallocatechin & $26 \cdot 7$ & & \\
\hline Epicatechin gallate & $23 \cdot 6$ & & \\
\hline Epigallocatechin gallate & $66 \cdot 2$ & & \\
\hline Maltodextrin & 74.9 & $310 \cdot 0$ & \\
\hline Microcrystalline cellulose & $71 \cdot 7$ & & \\
\hline Silicium dioxide & 1.5 & & \\
\hline Magnesium stearate & 1.5 & & \\
\hline Total (mg/capsule) & $310 \cdot 0$ & $310 \cdot 0$ & \\
\hline Treatment & Caffeine & Tea catechins & Maltodextrin \\
\hline PLAC (mg/capsule) & 0 & 0 & $310 \cdot 0$ \\
\hline $\begin{array}{l}\text { PLAC (mg/dose of three } \\
\text { capsules) }\end{array}$ & 0 & 0 & $930 \cdot 0$ \\
\hline PLAC (total mg/d) & 0 & 0 & $2790 \cdot 0$ \\
\hline GT (mg/capsule) & $26 \cdot 3$ & $134 \cdot 1$ & 74.9 \\
\hline $\begin{array}{l}\text { GT (mg/dose of three } \\
\text { capsules) }\end{array}$ & $78 \cdot 9$ & $402 \cdot 3$ & $224 \cdot 7$ \\
\hline GT (total mg/d) & $236 \cdot 7$ & $1206 \cdot 9$ & $674 \cdot 1$ \\
\hline
\end{tabular}

PLAC, placebo; GT, green tea.

‡GT: Sunphenon 100S (Taiyo Kagaku Co. Ltd, Mie, Japan) with added caffeine. their bladder. Height was measured to the nearest $0 \cdot 1 \mathrm{~cm}$ using a wall-mounted stadiometer (only during screening, model 220; Seca, Hamburg, Germany). BMI $\left(\mathrm{kg} / \mathrm{m}^{2}\right)$ was calculated as body weight $(\mathrm{kg})$ divided by height $(\mathrm{m})$ squared. The ratio of waist:hip circumference is an estimate of the distribution of body fat. The waist:hip ratio was calculated by dividing the waist circumference by the hip circumference. The waist circumference was measured at the site of the smallest circumference between the rib cage and the iliac crest, and the hip circumference was measured at the site of the largest circumference between the waist and the thighs. Both measurements were performed with subjects in the standing position.

Body composition was measured on days 4, 32 and 87 using the ${ }^{2} \mathrm{H}_{2} \mathrm{O}$ dilution technique (Schoeller et al. 1980; van Marken Lichtenbelt et al. 1994; Westerterp et al. 1995b). The dilution of the ${ }^{2} \mathrm{H}$ isotope is a measure of total body water (van Marken Lichtenbelt et al. 1994). In the evening, the subjects ingested a dose of ${ }^{2} \mathrm{H}$-enriched water $\left({ }^{2} \mathrm{H}_{2} \mathrm{O}\right)$ after collecting a background urine sample. After ingestion of the ${ }^{2} \mathrm{H}$ solution, no further fluid or food consumption was permitted. The following morning, the second urine sample (second voiding) was collected. The ${ }^{2} \mathrm{H}$ concentration in the urine samples was measured using an isotope ratio mass spectrometer (Micromass Optima, Manchester, UK). Total body water was obtained by dividing the measured ${ }^{2} \mathrm{H}$ dilution space by 1.04 to correct for exchange of the ${ }^{2} \mathrm{H}$ label with non-aqueous $\mathrm{H}$ in body solids (Schoeller et al. 1980). Fatfree mass (FFM) was calculated by dividing total body $\mathrm{H}_{2} \mathrm{O}$ by a hydrating factor of 0.73 . By subtracting FFM from body weight, fat mass (FM) was obtained. FM expressed as a percentage of body weight gives the percentage of body fat.

To determine the possible adverse effects of the treatments, systolic and diastolic blood pressure and heart rate were recorded during screening and on day 87 in the fasted state, on days 4 and 32 in the fasted state and each hour after the treatment using an automatic blood pressure monitor (OSZ 5 easy; Spreidel \& Keller GmBH and Co. KG, Jungingen, Germany).

\section{Questionnaires}

Attitude towards eating was analysed on days 4, 32 and 87 in the fasted state $(08.30 \mathrm{~h})$ using a validated Dutch translation of the Three Factor Eating Questionnaire (Stunkard \& Messick, 1985). Cognitive restrained and unrestrained eating behaviour (F1), emotional eating and disinhibition (F2) and subjective feeling of hunger (F3) were scored 0 or 1 and summed. Higher scores denote higher levels of restrained eating, disinhibited eating and predisposition to hunger, respectively. In addition, appetite ratings (mm; hunger, fullness, appetite, satiety, thirst, prospective food consumption, desire to eat) were scored on anchored $100 \mathrm{~mm}$ visual analogue scales on days 4, 32 and 87 in the fasted state $(08.30 \mathrm{~h})$ and on days 4 and $32180 \mathrm{~min}$ after ingestion of the capsules. Changes in mood and tolerance of the treatment were determined on day 87 in the fasted state $(08.30 \mathrm{~h})$, on days 4 and 32 in the fasted state and $180 \mathrm{~min}$ after ingestion of the treatment. Mood (relaxed, gloomy, pleasant, angry, afraid, sad) was assessed with $100 \mathrm{~mm}$ visual analogue scales, and tolerance was determined using a questionnaire on the occurrence of complaints (headache, fatigue, nausea, stomach ache, constipation, diarrhoea, etc.) and scored. Frequency classification was: 0, never; 1, seldom; 2, sometimes; 3 , relatively often; 4, often (5-point scale). 


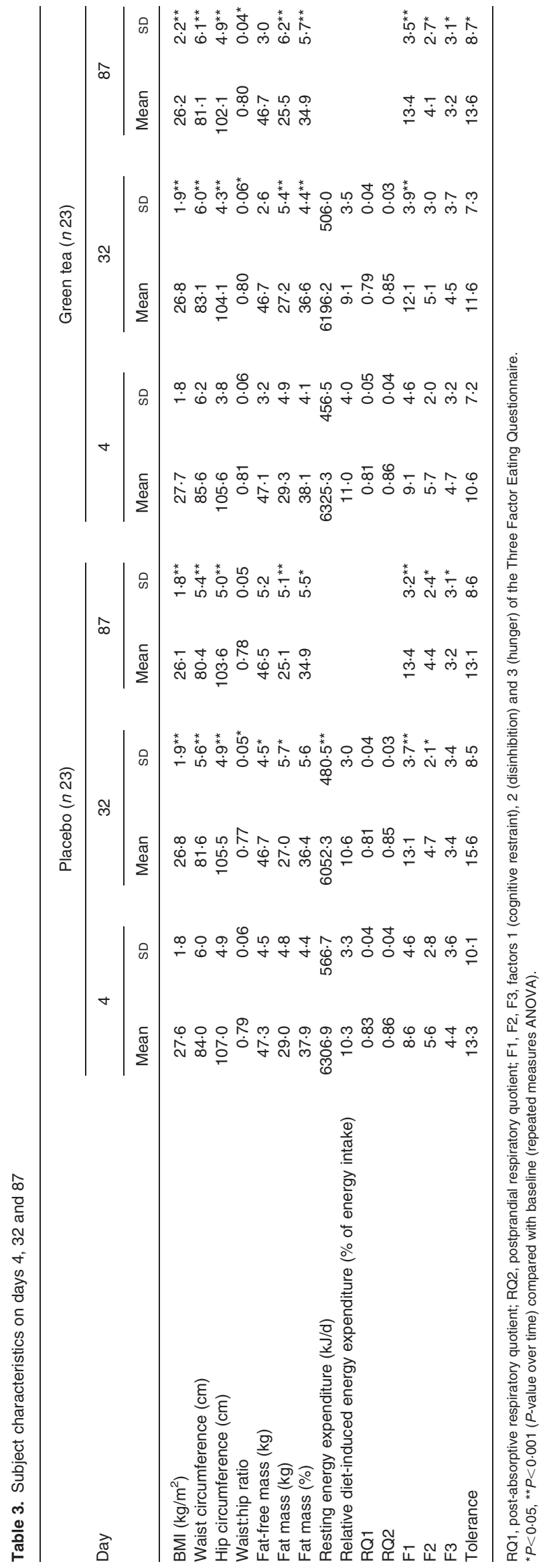



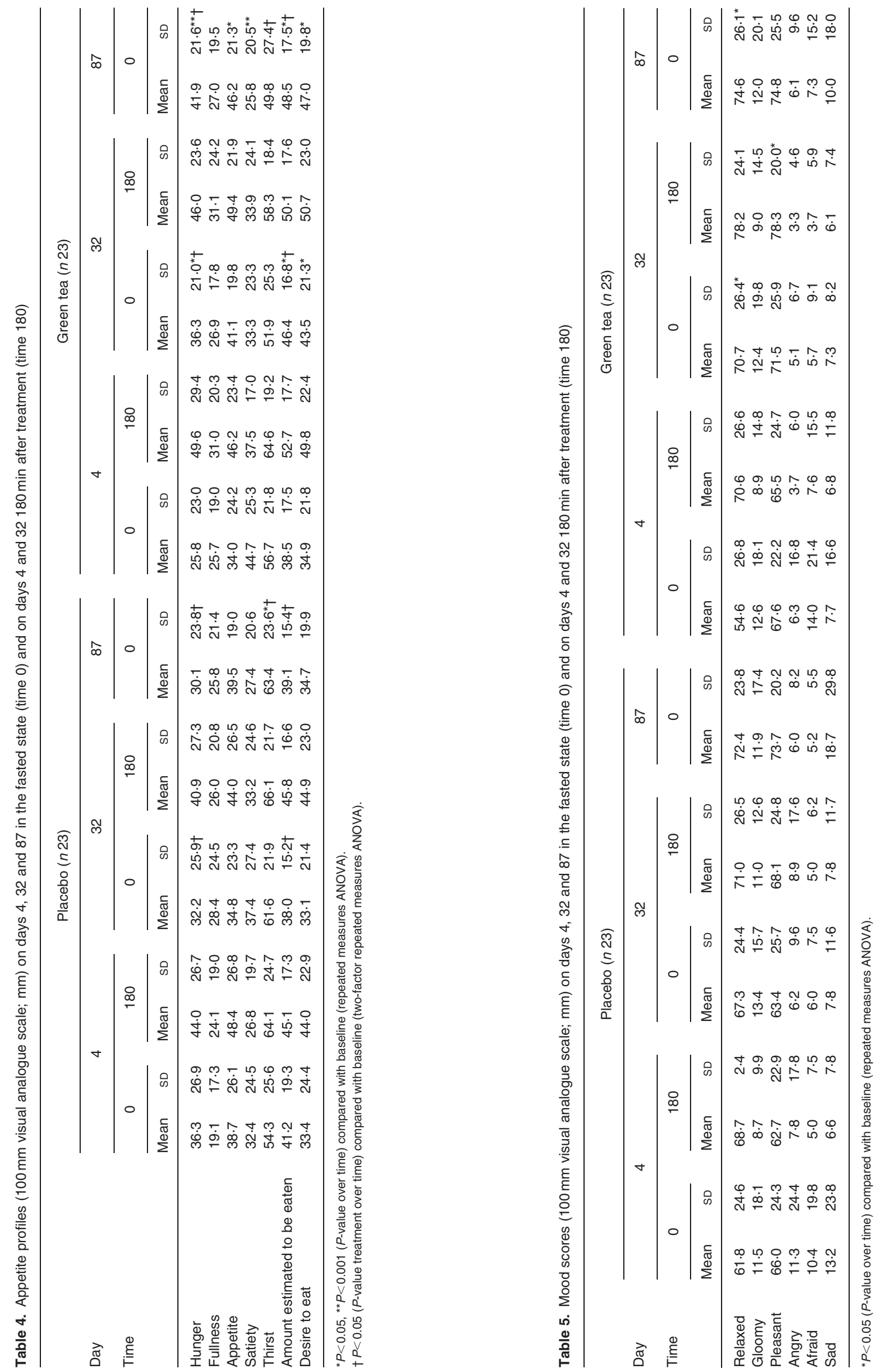


\section{Statistical analysis}

Data are presented as means and standard deviations. Data were analysed using Statview SE + Graphics (Abacus Concepts, Berkeley, CA, USA, 1988). Differences over time and between the treatments (PLAC or GT) over time were determined using one- and two-factor ANOVA with repeated measures. When appropriate, differences between groups were analysed using factorial ANOVA. Univariate and multivariate linear regression was used to determine the relationship between selected variables. The level for establishing significant differences was taken as $P<0.05$.

\section{Results}

Factorial ANOVA showed that none of the baseline (day 4) differences between the groups were statistically significant (Tables 3, 4, 5 and 6), indicating that the groups were well matched.

There was a significant reduction in body weight during the period of the LED $(P<0 \cdot 001)$. The PLAC group lost 2.45 (SD 1.4 ) and 4.19 (SD 1.3) kg, and the GT group 2.41 (SD 1.3) and 4.21 (SD 2.7) $\mathrm{kg}$ on days 32 and 87 respectively (Fig. 1). This decrease in body weight was not statistically different between treatments. As well as decreased body weight, there were reductions in BMI $(P<0 \cdot 001)$, waist circumference $(P<0 \cdot 001)$, hip circumference $(P<0.001)$ and waist:hip ratio $(P<0.05$ on day 32 in both groups and on day 87 in the GT group; Table 3). Furthermore, FM $(\%)$ was significantly decreased in the PLAC group on day $87(P<0.05)$ and in the GT group on days 32 and 87 $(P<0.001)$. FFM $(\mathrm{kg})$ was significantly decreased on day 32 in the PLAC group $(P<0 \cdot 05$, Table 3$)$. Reductions in BMI, waist and hip circumference, waist:hip ratio, FM and FFM were not, however, statistically different between treatments (Table 3).

There was a significant linear relation between REE $(\mathrm{kJ} / \mathrm{d})$ and FFM $(\mathrm{kg})$ on days 4 and 32 in both groups $(P<0 \cdot 001)$. As shown in Figs. 2 and 3, where REE is plotted as a function of FFM, the regression line on day 32 was lower than that on day 4 in the PLAC group but, remarkably, not in the GT group. To determine the changes in REE as a function of FFM and FM (regression of REE $v$. FFM and FM), this was calculated in each group by filling in the FFM $(\mathrm{kg})$ and FM $(\mathrm{kg})$ values from day 32 in the slope equation of day 4. Factorial ANOVA showed that the calculated REE on day 32 was significantly higher than the measured REE on day 32 in the PLAC group $(P<0.05)$ but not in the GT group. A comparison of the differences between the calculated and measured REE on day 32 between the PLAC and GT group did not show a significant difference (PLAC, 151.3 (SD $261.6) \mathrm{kJ} / \mathrm{d}$; GT, $54.4(\mathrm{SD} 389.4) \mathrm{kJ} / \mathrm{d} ; P=0.35$, one-factor ANOVA). Thus, the reduction in REE over time was not significantly different between the two treatments.

No time or treatment effect was observed on DEE and postabsorptive (RQ1) and postprandial (RQ2) RQ during the 4 weeks of weight loss (Table 3 ).

No treatment, yet a time, effect was observed with respect to dietary restraint in that the F1 score of the Three Factor Eating Questionnaire increased significantly over time $(P<0.001)$ on days 32 and 87 in both groups. The F2 (disinhibition) and F3 (hunger) scores were significantly decreased in both groups on day 87 (over time effect, $P<0 \cdot 05$; Table 3 ).

The appetite ratings are presented in Table 4 . The following time $\times$ treatment effects were shown $(P<0 \cdot 05)$. A significant increase in hunger and prospective food consumption was observed in the GT group relative to the PLAC group on days 32 and 87 in the fasted state $(P<0.05)$. Thirst increased significantly in the PLAC group on day $87(P<0.05)$ and decreased in the GT group $(P<0 \cdot 05)$.

Only an effect over time, but not treatment over time, was seen in the GT group on satiety, which decreased significantly $(P<0.001)$ on day 87 , whereas appetite and desire to eat increased significantly $(P<0 \cdot 05)$ in this group (Table 4$)$.

As shown in Table 5, the subjects in the GT group felt significantly more relaxed on day 32 and 87 in the fasted state compared with baseline $(P<0.05$, effect over time). No other changes in mood were found.

Systolic and diastolic blood pressure both decreased during the weight-loss period (Table 6), with no difference in treatments over time. There was no change in heart rate during weight loss and no differences between treatments (Table 6). The occurrence of complaints was significantly increased on day 87 in the GT group $(P<0.05$, effect over time) but remained low (Table 3).

Table 6. Systolic blood pressure (SBP), diastolic blood pressure (DBP) and heart rate (HR) on days 4,32 and 87 in the fasted state (t0) and on days 4 and 32 60,120 and 180 min after treatment $(\mathrm{t} 60, \mathrm{t} 120, \mathrm{t} 180)$

\begin{tabular}{|c|c|c|c|c|c|c|c|c|c|c|c|c|c|}
\hline & & \multicolumn{6}{|c|}{ Placebo (n 23) } & \multicolumn{6}{|c|}{ Green tea (n 23) } \\
\hline & & \multicolumn{2}{|c|}{4} & \multicolumn{2}{|c|}{32} & \multicolumn{2}{|c|}{87} & \multicolumn{2}{|c|}{4} & \multicolumn{2}{|c|}{32} & \multicolumn{2}{|c|}{87} \\
\hline \multirow[t]{3}{*}{$\mathrm{SBP}(\mathrm{mmHg})$} & to & 122.5 & $13 \cdot 2$ & $119 \cdot 0$ & 8.9 & $115 \cdot 9$ & $9 \cdot 7^{\star}$ & $127 \cdot 3$ & $11 \cdot 8$ & 121.0 & $8 \cdot 5^{\star}$ & $117 \cdot 3$ & $8 \cdot 3^{\star *}$ \\
\hline & $\mathrm{t} 60$ & $123 \cdot 0$ & 9.5 & $117 \cdot 3$ & $7 \cdot 1^{*}$ & & & $127 \cdot 7$ & $12 \cdot 5$ & $121 \cdot 6$ & $9 \cdot 8^{*}$ & & \\
\hline & $\mathrm{t} 120$ & $122 \cdot 4$ & $10 \cdot 4$ & $117 \cdot 1$ & $7 \cdot 3^{*}$ & & & $130 \cdot 6$ & 13.9 & $120 \cdot 4$ & $7 \cdot 9^{\star}$ & & \\
\hline \multirow[t]{4}{*}{$\mathrm{DBP}(\mathrm{mmHg})$} & to & 78.6 & 8.9 & 76.6 & 6.9 & $77 \cdot 2$ & 6.4 & $80 \cdot 0$ & $12 \cdot 0$ & 74.7 & $9 \cdot 5^{\star}$ & $76 \cdot 0$ & $8.5^{\star}$ \\
\hline & $\mathrm{t} 60$ & $75 \cdot 7$ & $6 \cdot 1$ & $72 \cdot 0$ & $5 \cdot 3^{*}$ & & & $79 \cdot 3$ & 11.7 & $72 \cdot 9$ & $10 \cdot 5^{\star}$ & & \\
\hline & $\mathrm{t} 120$ & $76 \cdot 7$ & 7.5 & $74 \cdot 1$ & $5 \cdot 7^{\star}$ & & & $81 \cdot 3$ & $12 \cdot 3$ & $75 \cdot 4$ & $10 \cdot 7^{\star}$ & & \\
\hline & $\mathrm{t} 180$ & 79.9 & $7 \cdot 8$ & $75 \cdot 2$ & $5 \cdot 5^{\star}$ & & & 82.9 & 11.5 & 75.7 & $11 \cdot 7^{\star \star}$ & & \\
\hline \multirow[t]{4}{*}{ HR (beats/min) } & to & $66 \cdot 2$ & $6 \cdot 8$ & $64 \cdot 1$ & $8 \cdot 3$ & $69 \cdot 4$ & $9 \cdot 6$ & $65 \cdot 3$ & 7.7 & 63.2 & 7.6 & $66 \cdot 8$ & 8.7 \\
\hline & $\mathrm{t} 60$ & $66 \cdot 2$ & $7 \cdot 2$ & 65.8 & 8.6 & & & 64.7 & $7 \cdot 7$ & 64.7 & 9.5 & & \\
\hline & $\mathrm{t} 120$ & $64 \cdot 7$ & 6.9 & 63.0 & 9.0 & & & 63.7 & $6 \cdot 6$ & $62 \cdot 0$ & $7 \cdot 2$ & & \\
\hline & t180 & 64.5 & $7 \cdot 8$ & 63.5 & 8.6 & & & 64.6 & $9 \cdot 3$ & $62 \cdot 5$ & $7 \cdot 2$ & & \\
\hline
\end{tabular}

${ }^{*} P<0.05,{ }^{* \star} P<0.001$ ( $P$-value over time) compared with baseline (repeated measures ANOVA). 


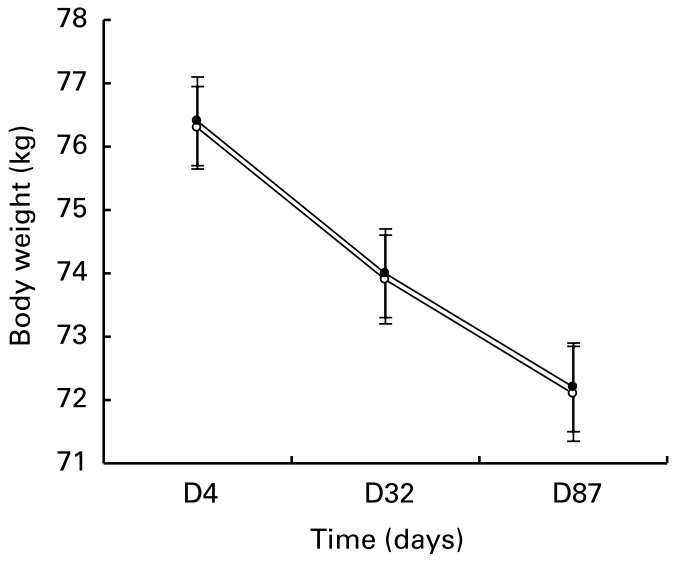

Fig. 1. Change in body weight over time in the placebo $\circ$ and green tea • groups. Values are means with their standard errors shown by vertical bars. No significant differences were seen between the two groups at any time.

\section{Discussion}

This study has shown that GT extract had no added benefits for any measures of body weight or body composition when used as a part of a LED (meal-replacement diet plan).

In contrast, Japanese studies show that the long-term (12-week) administration of tea catechins in a dose of $400-600 \mathrm{mg} / \mathrm{d}$ in human subjects would reduce body fat and body-fat parameters and might be useful in the prevention and reduction of obesity (Hase et al. 2001; Nagao et al. 2001; Tsuchida et al. 2002). The Japanese participants were, however, studied during a weight-maintenance period, with limited caffeine intake, whereas our subjects were studied in a weight-loss period. Furthermore, a recent Japanese article found that the daily consumption of $340 \mathrm{ml}$ tea containing $690 \mathrm{mg}$ catechins (GT extract) for 12 weeks reduced body weight, BMI, waist circumference and body fat compared with the control group, who had a daily consumption of $340 \mathrm{ml}$ tea with $22 \mathrm{mg}$ catechins (Nagao et al. 2005). In addition, unlike the Japanese studies, it was found by Kovacs et al. (2004), who investigated the effects of GT in 104 subjects (BMI $25-35 \mathrm{~kg} / \mathrm{m}^{2}$ ) participating in a very-low-energy diet intervention of 4 weeks followed by a weight maintenance period of 13 weeks, that weight maintenance after $7.5 \%$ weight loss was not affected by GT treatment.

In the present study, the first data assessing the effect of GT on REE along with a LED, i.e. during negative energy balance, are

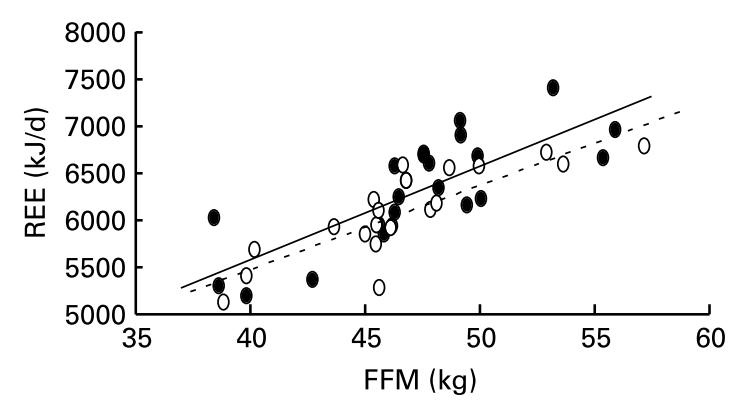

Fig. 2. Resting energy expenditure (REE; $k J / d$ ) as a function of fat-free mass (FFM; kg) plotted for day $4(\mathrm{O}$, trendline -$)$ and day $32(\bullet$, trendline --) in the placebo group. Regression equation for day 4: REE $=99.43 F F M$ $+1605.6\left(R^{2}=0.62\right)$; regression equation for day 32: $\mathrm{REE}=89.5 \mathrm{FFM}$ $+1896.9\left(R^{2}=0.7\right)$.

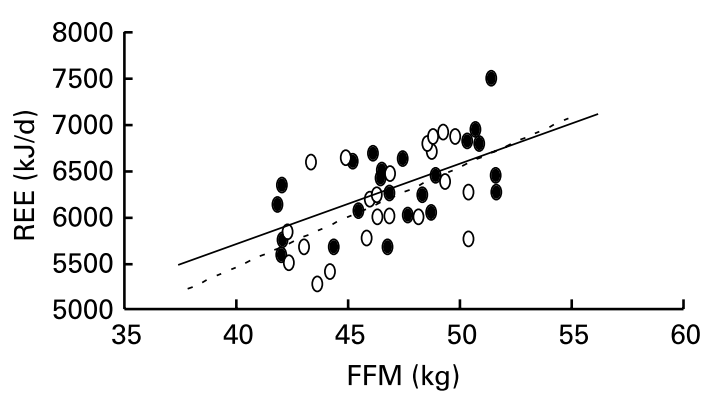

Fig. 3. Resting energy expenditure (REE; $\mathrm{kJ} / \mathrm{d})$ as a function of fat-free mass (FFM; kg) plotted for day $4(\mathrm{O}$, trend line - ) and day $32(\bullet$, trend line --) in the green tea group. Regression equation for day 4: REE $=86.62 \mathrm{FFM}$ $+2240.7\left(R^{2}=0.37\right)$; regression equation for day 32: REE $=108.02 \mathrm{FFM}$ $+1132.9\left(R^{2}=0.32\right)$.

reported. We hypothesised that the ingestion of GT (225 mg caffeine and $1125 \mathrm{mg}$ catechins/d) could offset the reduction in REE that occurs during a LED. However, the difference between groups over time was not statistically significant. The present study shows that REE as a function of both FFM and FM did not decrease significantly over time when GT, independent of habitual caffeine intake, was ingested together with a LED (60\% of predicted EE), whereas the decrease in REE was significant in the PLAC group, yet no treatment over time effect was observed. Attenuation of a reduction in REE during weight loss has been shown before (Ravussin \& Bogardus, 1992; Astrup et al. 1999; Menozzi et al. 2000). In the present study, however, a robust limitation of REE reduction during a LED was not achieved by GT, and further research is required.

Our study design was based on observations by Dulloo et al. (1999, 2000), who have recently demonstrated in vitro and in vivo that GT causes a stimulation of thermogenesis that cannot be explained per se by its caffeine content. The $24 \mathrm{~h} \mathrm{EE}$ with GT extract was significantly greater than that with both the placebo and caffeine (Dulloo et al. 1999). The study by Dulloo et al. (1999) was performed with young men (age 25 (SD 1) y, BMI $25 \cdot 1$ (SD 1.2) $\mathrm{kg} / \mathrm{m}^{2}$ ), whereas our subjects were women. The difference in gender possibly plays a role as women have higher circulating leptin concentrations than men (Trayhurn, 2001). Furthermore, the subjects in the study by Dulloo et al. were relatively low consumers of caffeine $(100-200 \mathrm{mg} / \mathrm{d})$, and they had to abstain from caffeine-containing foods and beverages the day before and during the experiment. The ingestion of GT capsules provided daily a total of $150 \mathrm{mg}$ caffeine (Dulloo et al. 1999). In contrast, our subjects had a habitual intake of $300 \mathrm{mg} /$ $\mathrm{d}$ before and during the study, and the ingestion of GT capsules provided $236.7 \mathrm{mg}$ caffeine/d. It is possible that prior habitual caffeine use led to tolerance to the anticipated effects of caffeine, rendering the GT supplement ineffective.

No difference in body weight loss was seen between the experimental and control groups. This cannot be explained by the attitude towards eating. The Three Factor Eating Questionnaire scores showed a normal profile (more dietary restraint, less disinhibition and hunger after the LED) and did not differ statistically between the groups (Westerterp-Plantenga et al. 1998; Pasman et al. 1999b). One possible explanation is the significant differences between the groups with respect to the appetite parameters, in that the GT group became more hungry and less thirsty, and had an increased prospective food intake, compared with PLAC. Furthermore, the GT group was 
less satiated and had an increased appetite and desire to eat in comparison with baseline. The downregulation of the leptin release through stimulation of the sympathetic nervous system by GT may play a role since leptin reduces appetite (Trayhurn et al. 1999; Rayner \& Trayhurn, 2001). To offset the increase in hunger with GT, it may be of value to look at the effect of GT given together with a satiating agent such as guar gum (Kovacs et al. 2001, 2002).

It is possible that the thermogenic efficacy of GT is weak in this study as food restriction (LED) is a state of reduced sympathetic activity (reduced noradrenaline release). Owing to this reduced noradrenaline release, the pharmacologically active ingredients (tea catechins and caffeine) have not many "negative modulators' to inhibit. Dulloo et al. showed in vitro that, in the absence of increased noradrenaline release from sympathetic nerves, catechins, caffeine or catechins + caffeine had only mild effects on the respiration rate of brown adipose tissue (Dulloo et al. 2000).

In contrast to Dulloo et al. (1999), no stimulation of GT on fat oxidation was found. Dulloo et al. measured $24 \mathrm{~h} R \mathrm{RQ}$, whereas in the present study we measured $30 \mathrm{~min}$ post-absorptive RQ and 180 min postprandial RQ. Since breakfast stimulates carbohydrate oxidation and not fat oxidation, no effect of GT on fat oxidation was seen. Another explanation is that the RQ is already low during weight loss induced by a LED.

Systolic and diastolic blood pressure and heart rate were not affected by GT. This is in accordance with a study of Hodgson et al. (1999), who found that the regular consumption of GT (five $200 \mathrm{ml}$ cups/d, $50 \mathrm{mg}$ caffeine/cup and tea bags containing $2 \mathrm{~g}$ tea leaves) over $7 \mathrm{~d}$ had no significant effect on ambulatory blood pressure. The reduction in blood pressure is probably caused by weight loss or by the fact that the subjects felt more relaxed on days 32 and 87.

Taken together, 12-week GT administration during a LED, independent of habitual caffeine intake, had no effect on measures of body weight or body composition at 4 weeks or 3 months. This may be due to increased hunger with GT treatment and the lack of a robust effect on the prevention of decrease in REE. With respect to the safety of the treatment, no adverse events occurred.

For future research, we recommend testing the combination of GT with another thermogenic ingredient, for example capsaicin, assessing a possible synergism, and adding a satiating agent such as guar gum (Kovacs et al. 2001, 2002; Yoshioka et al. 2001; Lejeune et al. 2003). Another possibility is the administration of GT in conjunction with approaches that counteract the fall in sympathetic activity during a LED regimen.

\section{Acknowledgements}

We thank Tanja Adam, Arnold Kester, Paul Schoffelen, Joan Senden and Loek Wouters for their contribution to the study. This study was supported by Unilever Food and Health Research Institute, Unilever R\&D Vlaardingen, Vlaardingen, The Netherlands. The Slim.Fast products were donated by Unilever Bestfoods Nederland BV.

\section{References}

Astrup A, Gotzsche PC, van de Werken K, Ranneries C, Toubro S, Raben A \& Buemann B (1999) Meta-analysis of resting metabolic rate in formerly obese subjects. Am J Clin Nutr 69, 1117-1122.
Astrup A, Toubro S, Cannon S, Hein P, Breum L \& Madsen J (1990) Caffeine: a double-blind, placebo-controlled study of its thermogenic, metabolic, and cardiovascular effects in healthy volunteers. Am J Clin Nutr 51, 759-767.

Borchardt RT \& Huber JA (1975) Catechol O-methyltransferase. Structure-activity relationships for inhibition by flavonoids. J Med Chem 18, 120-122.

Bracco D, Ferrarra J-M, Arnaud MJ, Jequier E \& Schutz Y (1995) Effects of caffeine on energy metabolism, heart rate, and methylxanthine metabolism in lean and obese women. Am J Physiol 269, E671-E678.

Chantre P \& Lairon D (2002) Recent findings of green tea extract AR25 (Exolise) and its activity for the treatment of obesity. Phytomedicine $\mathbf{9}$, $3-8$.

Dulloo AG, Duret C, Rohrer D, Girardier L, Mensi N, Fathi M, Chantre P \& Vandermander J (1999) Efficacy of a green tea extract rich in catechin-polyphenols and caffeine in increasing 24-h energy expenditure and fat oxidation in humans. Am J Clin Nutr 70, 1040-1045.

Dulloo AG, Geissler CA, Horton T, Collins A \& Miller DS (1989) Normal caffeine consumption: influence on thermogenesis and daily energy expenditure in lean and postobese human volunteers. Am J Clin Nutr 49, 44-50.

Dulloo AG, Seydoux J \& Girardier L (1992) Potentiation of the thermogenic antiobesity effects of ephedrine by dietary methylxanthines: adenosine antagonism or phosphodiesterase inhibition. Metabolism 41, $1233-1241$.

Dulloo AG, Seydoux J, Girardier L, Chantre P \& Vandermander J (2000) Green tea and thermogenesis: interactions between catechinpolyphenols, caffeine and sympathetic activity. Int $J$ Obes 24, 252-258.

Graham HN (1992) Green tea composition, consumption, and polyphenol chemistry. Prev Med 21, 334-350.

Hase T, Komine Y, Meguro S, et al. (2001) Anti-obesity effects of tea catechins in humans. J Oleo Sci 50, 599-605.

Hodgson JM, Puddey IB, Burke V, Beilin LJ \& Jordan N (1999) Effects on blood pressure of drinking green and black tea. J Hypertens 17, 457-463.

Hulshof KF, Brussaard JH, Kruizinga AG, Telman J \& Lowik MR (2003) Socio-economic status, dietary intake and $10 \mathrm{y}$ trends: the Dutch National Food Consumption Survey. Eur J Clin Nutr 57, 128-137.

Kao Y-H, Hiipakka RA \& Liao S (2000) Modulation of endocrine systems and food intake by green tea epigallocatechin gallate. Endocrinology 141, 980-987.

Kovacs EM, Lejeune MP, Nijs I \& Westerterp-Plantenga MS (2004) Effects of green tea on weight maintenance after body-weight loss. Br J Nutr 91, 431-437.

Kovacs EM, Westerterp-Plantenga MS, Saris WH, Goossens I, Geurten P $\&$ Brouns F (2001) The effect of addition of modified guar gum to a low-energy semisolid meal on appetite and body weight loss. Int $J$ Obes 25, 307-315.

Kovacs EM, Westerterp-Plantenga MS, Saris WH, Melanson KJ, Goossens I, Geurten P \& Brouns F (2002) The effect of guar gum addition to a semisolid meal on appetite related to blood glucose, in dieting men. Eur J Clin Nutr 56, 771-778.

Lejeune MPGM, Kovacs EMR \& Westerterp-Plantenga MS (2003) Effect of capsaicin on substrate oxidation and weight maintenance after modest body-weight loss in human subjects. Br J Nutr 90 , $1-10$.

Menozzi R, Bondi M, Baldini A, Venneri MG, Velardo A \& Del Rio G (2000) Resting metabolic rate, fat-free mass and catecholamine excretion during weight loss in female obese patients. Br J Nutr 84, $515-520$.

Nagao T, Meguro S, Soga S, et al. (2001) Tea catechins suppress accumulation of body fat in humans. J Oleo Sci 50, 717-728.

Nagao T, Komine Y, Soga S, Meguro S, Hase T, Takana Y \& Tokimitsu I (2005) Ingestion of a tea rich in catechins leads to a reduction in body fat and malondialdehyde-modified LDL in men. Am J Clin Nutr 81, $122-129$. 
Pasman WJ, Saris WH, Muls E, Vansant G \& Westerterp-Plantenga MS (1999a) Effect of exercise training on long-term weight maintenance in weight-reduced men. Metabolism 48, 15-21.

Pasman WJ, Saris WHM \& Westerterp-Plantenga MS (1999b) Predictors of weight maintenance. Obes Res 7, 43-50.

Ravussin E \& Bogardus C (1992) A brief overview of human energy metabolism and its relationship to essential obesity. Am J Clin Nutr 55, 242S-245S.

Ravussin E, Lillioja S, Knowler WC, Christin L, Freymond D, Abbott WG, Boyce V, Howard BV \& Bogardus C (1988) Reduced rate of energy expenditure as a risk factor for body-weight gain. $N$ Engl $J$ Med 318, 467-472.

Rayner DV \& Trayhurn P (2001) Regulation of leptin production: sympathetic nervous system interactions. J Mol Med 79, 8-20.

Schoeller DA, van Santen E, Peterson DW, Dietz W, Jaspan J \& Klein PD (1980) Total body water measurement in humans with $18 \mathrm{O}$ and $2 \mathrm{H}$ labeled water. Am J Clin Nutr 33, 2686-2693.

Schoffelen PFM, Westerterp KR, Saris WHM \& Ten Hoor F (1997) A dual-respiration chamber system with automated calibration. $J$ Appl Physiol 83, 2064-2072.

Stunkard AJ (1996) Current views on obesity. Am J Med 100, 230-236.

Stunkard AJ \& Messick S (1985) The three-factor eating questionnaire to measure dietary restraint, disinhibition and hunger. J Psychosom Res 29, 71-83.

Trayhurn P (2001) Biology of leptin - its implications and consequences for the treatment of obesity. Int J Obes 25, Suppl. 1, S26-S28.

Trayhurn P, Hoggard N, Mercer JG \& Rayner DV (1999) Leptin: fundamental aspects. Int J Obes 23, Suppl. 1, 22-28.

Tsuchida T, Itakura H \& Nakamura H (2002) Reduction of body fat in humans by long-term ingestion of catechins. Prog Med 22, 2189-2203. van Boxtel MP, Schmitt JA, Bosma H \& Jolles J (2003) The effects of habitual caffeine use on cognitive change: a longitudinal perspective. Pharmacol Biochem Behav 75, 921-927.

van Dam RM \& Feskens EJ (2002) Coffee consumption and risk of type 2 diabetes mellitus. Lancet 360, 1477-1478.

van Marken Lichtenbelt WD, Westerterp KR \& Wouters L (1994) Deuterium dilution as a method for determining total body water: effect of test protocol and sampling time. Br J Nutr 72, 491-497.

Wadden TA, Stunkard AJ \& Liebschutz J (1988) Three-year follow-up of the treatment of obesity by very low calorie diet, behavior therapy, and their combination. J Consult Clin Psychol 56, 925-928.

Weir JBDV (1949) New methods for calculating metabolic rate with special references to protein metabolism. J Physiol 109, 1-9.

Weisburger JH (1997) Tea and health: a historical perspective. Cancer Lett 114, 315-317.

Westerterp KR, Donkers JHHLM, Frederix EWHM \& Boekhoudt P (1995a) Energy intake, physical activity and body weight: a simulation model. Br J Nutr 73, 337-347.

Westerterp KR, Wouters L \& van Marken Lichtenbelt WD (1995b) The Maastricht protocol for the measurement of body composition and energy expenditure with labeled water. Obes Res 3, Suppl. 1, 49-57.

Westerterp-Plantenga MS, Kempen KPG \& Saris WHM (1998) Determinants of weight maintenance in women after diet-induced weight reduction. Int $J$ Obes 22, 1-6.

World Health Organization (2000) Obesity: preventing and managing the global epidemic. Report of a WHO consultation. World Health Organ Tech Rep Ser 894, i-xii, 1-253.

Yoshioka M, Doucet E, Drapeau V, Dionne I \& Tremblay A (2001) Combined effects of red pepper and caffeine consumption on $24 \mathrm{~h}$ energy balance in subjects given free access to foods. Br J Nutr 85, 203-211. 